Supporting Information

\title{
Engineering bioactive hybrid coating for in vitro corrosion control of magnesium and its alloy
}

\author{
Md. Mostafizur Rahman a, Rajkamal Balua, Amanda Abraham ${ }^{\text {b }}$, Naba K.$$
\text { Dutta }^{\mathrm{a}, *} \text { and Namita Roy Choudhurya,* }
$$ \\ ${ }^{a}$ Chemical and Environmental Engineering, School of Engineering, RMIT University, \\ Melbourne, VIC 3000, Australia \\ ${ }^{\mathrm{b}}$ ARC Centre of Excellence for Nanoscale BioPhotonics, School of Science, RMIT University, \\ Melbourne, VIC 3000, Australia \\ *Corresponding author E-mail address: \\ naba.dutta@rmit.edu.au (N.K.D.) \\ namita.choudhury@rmit.edu.au (N.R.C.)
}



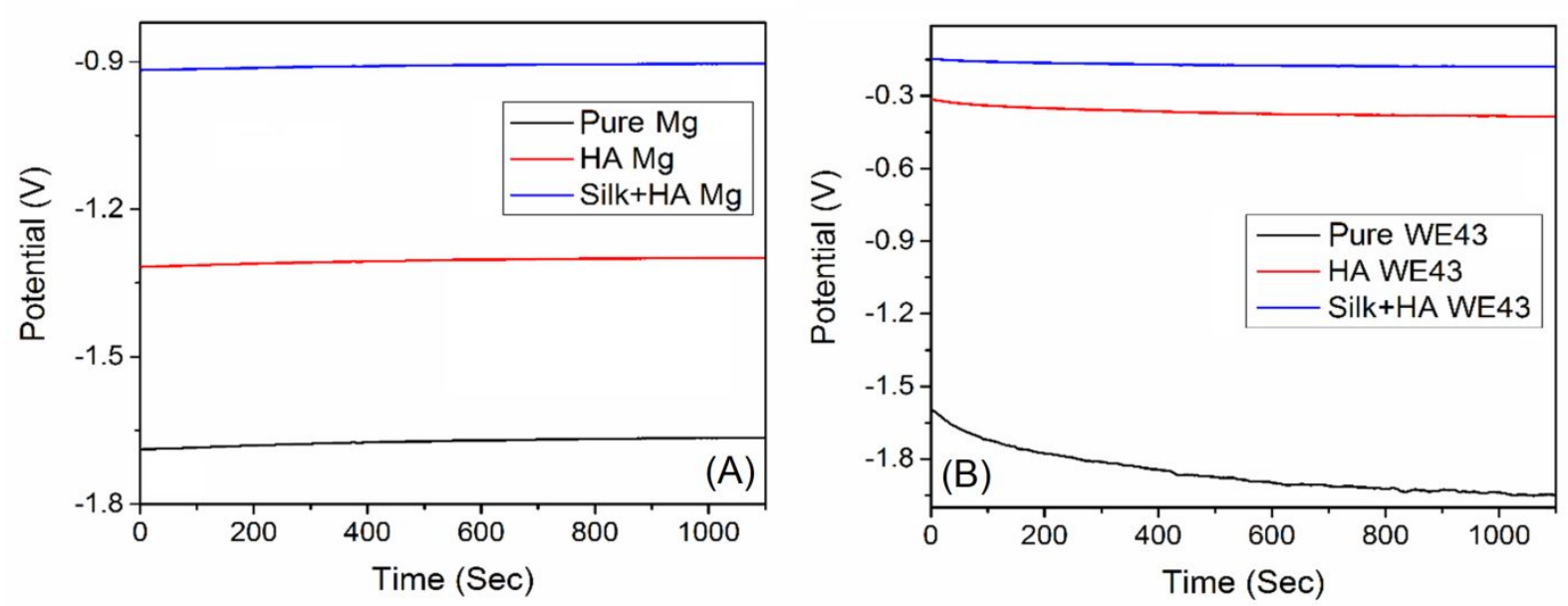

Figure S1. Open circuit potential curves of pure, HA and Silk+HA coated (A) Mg and (B) WE43 Mg alloy. 